\title{
Orexin A protects cells from apoptosis by regulating FoxO1 and mTORC1 through the OX1R/PI3K/AKT signaling pathway in hepatocytes
}

\author{
SHU-JING JU ${ }^{1}$, YUYAN ZHAO ${ }^{1}$, XIAOCEN CHANG ${ }^{1}$ and LEI GUO ${ }^{2}$ \\ Departments of ${ }^{1}$ Endocrinology, ${ }^{2}$ Orthopedic Surgery, First Affiliated Hospital, \\ China Medical University, Shenyang, Liaoning 110001, P.R. China \\ Received January 11, 2014; Accepted April 25, 2014
}

DOI: $10.3892 /$ ijmm.2014.1769

\begin{abstract}
Orexin A and B are multifunctional neuropeptides that are involved in the regulation of food intake, energy metabolism, glucose regulation and wakefulness. They signal through two G-protein-coupled receptors (GPCR): orexin receptor $1(\mathrm{OX} 1 \mathrm{R})$ and orexin receptor $2(\mathrm{OX} 2 \mathrm{R})$. Previous studies have shown that orexins interact with PI3K/AKT signaling pathways through OX1R-coupling in other cell types, but are seldom involved in hepatocytes. In the present study, reverse transcription (RT)-PCR and western blot analysis revealed that OX1R mRNA expression and activation in rat hepatocytes in vitro were upregulated by exogenous orexin $\mathrm{A}\left(10^{-10}\right.$ to $\left.10^{-6} \mathrm{M}\right)$ in a dose-dependent manner. The result showed that orexin A affects increasing cell proliferation and protects cells from apoptosis. Additionally, inhibition studies showed that orexin A induced forkhead box O1 (FoxO1) and mammalian target of rapamycin 1 (mTORC1) phosphorylation, while OX1R antagonist (SB334867, 10-6 M), AKT antagonist (PF-04691502, 10-6 M), FoxO1 inhibitor (AS1842856, 10-6 M) or mTORC1 inhibitor (everolimus, $10^{-5} \mathrm{M}$ ) blocked these effects of orexin A. The results of the present study showed a possible effect of orexin A on cell apoptosis in regulating FoxO1 and mTORC1 through the OX1R/PI3K/AKT signaling pathway in rat hepatocytes.
\end{abstract}

\section{Introduction}

Orexin A and B, also known as hypocretins are neuropeptides identified by two groups in $1998(1,2)$. They articulate their signaling cascades via two G-protein-coupled receptors (GPCRs): orexin receptor 1 (OX1R) and orexin

Correspondence to: Professor Yuyan Zhao, Department of Endocrinology, First Affiliated Hospital, China Medical University, 155 Nanjing North Street, Shenyang, Liaoning 110001, P.R. China E-mail: g572@sina.com

Key words: orexin A, orexin receptor 1, PI3K/AKT, forkhead box O1, mammalian target of rapamycin 1, cell apoptosis receptor 2 (OX2R) $(2,3)$. Orexin A and B synthesize neurons located in the lateral hypothalamus that project to other regions of brain, including stem nuclei and thalamus, forebrain region and spinal cord (4-6). Orexins and orexin receptors are involved in many physiological processes, including food intake, sleepawake, reproductive behavior, and energy homeostasis (7-10). OX1R has a wide tissue distribution in the central nervous system and in peripheral tissues, including adipose tissue, gut, pancreatic, adrenal gland and testis $(11,12)$. AKT is able to phosphorylate a large number of intracellular targets (13). Two evolutionarily conserved downstream effectors of AKT, FoxO1 and mTORC1, were investigated in the present study.

Forkhead box O1 (FoxO1) is a prominent member of the forkhead box family and is involved in the regulation of metabolism, cell proliferation, differentiation, cell cycle progression, apoptosis and cell death in many cell types (14-17). The PI3K/AKT signaling pathway changes FoxO1 transcriptional activities by regulating threonine, serine and the phosphorylation of FoxO1 $(14,18)$. Phosphorylated FoxO1 translocates from the nucleus to cytosol and loses its transcriptional activity in liver (16-19).

Mammalian target of rapamycin 1 (mTORC1) is another downstream target of the PI3K/AKT signaling pathway (20). mTORC1 regulates cell growth and proliferation largely through the increase in protein synthesis $(20,21)$. mTORC1 elevates mRNA translation by phosphorylating and activating S6K1, and phosphorylating and inhibiting the elF4E-binding protein, a repressor of mRNA translation (20-22). AKT can activate mTORC1 through direct phosphorylation of the tuberous sclerosis complex $2(21,22)$.

Orexin A is known to play a key role in the PI3K/AKT signaling pathway in many tyeps of cells $(13,23-25)$, but there is no exact evidence concerning orexin A acting on PI3K/ AKT transduction in hepatocytes. The aim of this study was to determine whether AKT is required for cell proliferation and apoptosis by changing activities of the downstream targets, FoxO1 and mTORC1. The role of FoxO1 and mTORC1 in cell proliferation and apoptosis in the involvement of PI3K/AKT pathways regulated by orexin A in rat hepatocytes was examined. The results provide insight into the mechanisms by which orexin A contributes to cell cycle processes and metabolisms, thus having important implications for clinical therapy. 


\section{Materials and methods}

Animals. Thirty male Sprague-Dawley rats (3-4 weeks old, weighing 200-250 g) were obtained from China Medical University and bred in our laboratory. The temperature was maintained at $22 \pm 2^{\circ} \mathrm{C}$ with a constant 12 -h light-dark cycle (6:00 a.m. to 6:00 p.m.). The rats received a normal diet (from commercial diet) of standard laboratory chow (20\% protein, 15\% fat, 65\% carbohydrate diet) (China Medical University Laboratory Animal Center, Shenyang, China). The animal experiments were approved by the Ethics Committee of the First Affiliated Hospital of China Medical University.

Reagents. Orexin A was obtained from Sigma (St. Louis, MO, USA). RPMI-1640 medium and fetal bovine serum were purchased from Gibco (Grand Island, NY, USA). The AKT inhibitor, LY294002, was purchased from Selleck Chemicals (Houston, TX, USA). FoxO1 inhibitor AS1842856 and mTORC1 inhibitor everolimus were obtained from Abcam (Cambridge, UK). OX1R-specific antagonist SB334867 was obtained from Tocris Bioscience (Minneapolis, MN, USA). The Cell-Death Detection ELISA kit and Cell Proliferation ELISA BrdU colorimetric kit were purchased from Roche Diagnostics (Penzberg, Germany). Total/phospho-AKT (s473) polyclonal antibody, total/phospho-FoxO1 polyclonal antibody and total/phospho-mTORC1 polyclonal antibody, $\beta$-actin (c4): sc-47778 and OX1R antibody were all obtained from Abcam.

Isolation and culturing of rat hepatocytes. Rat livers were decapsulated and incubated with $0.5 \mathrm{mg} / \mathrm{ml}$ collagenase type IV (Invitrogen, Grand Island, NY, USA) for $30 \mathrm{~min}$ at $37^{\circ} \mathrm{C}$ in a shaker at 160 cycles $/ \mathrm{min}$. The cell suspension was collected by centrifugation at $800 \mathrm{rpm}$ for $10 \mathrm{~min}$. To obtain purified hepatocytes, the crude cell suspension was centrifuged on a Percoll gradient (20, 40, 60 and 90\% Percoll in PBS solution; Sigma) and subsequently centrifuged at $800 \mathrm{rpm}$ for $20 \mathrm{~min}$ at $4^{\circ} \mathrm{C}$. Fractions containing hepatocytes were collected and centrifuged in a continuous, self-generating density gradient starting with $60 \%$ Percoll at $2,000 \mathrm{rpm}$ for $30 \mathrm{~min}$ at $4^{\circ} \mathrm{C}$. The purified hepatocytes were cultured with RPMI-1640 medium (Invitrogen) supplemented with 10\% bovine serum albumin (HyClone, Beijing, China), $100 \mathrm{IU} / \mathrm{ml}$ penicillin and $100 \mu \mathrm{g} / \mathrm{ml}$ streptomycin (Xianfeng, Shanghai, China) and cultured $\left(10^{6} \mathrm{cells} / \mathrm{ml}\right.$ per dish $)$ at $37^{\circ} \mathrm{C}$ in a humidified incubator with $5 \% \mathrm{CO}_{2}$ for $24 \mathrm{~h}$.

Cell proliferation assays. Cells $\left(2 \times 10^{3}\right.$ cells/well) were seeded in 96-well plates and cultured for $24 \mathrm{~h}$. To synchronize cell cycles, the cells were serum-deprived for $24 \mathrm{~h}$ and then treated with test agents for an additional $24 \mathrm{~h}$. BrdU incorporation into DNA was measured by the cell proliferation ELISA BrdU colorimetric kit (Roche Diagnostics). The cells were incubated with $\mathrm{BrdU}$ fresh medium at $37^{\circ} \mathrm{C}$ and $5 \% \mathrm{CO}_{2}$ for $12 \mathrm{~h}$ and fixed with $200 \mu 1$ of fixative/denaturing solution for $30 \mathrm{~min}$ at room temperature. Peroxidase-conjugated BrdUrd antibody was added to each well and incubated for $1 \mathrm{~h}$. After washing thoroughly, the bound peroxidase-conjugated BrdUrd antibody was quantified with peroxidase substrate tetramethylbenzidine. BrdUrd absorbance was measured at $440 \mathrm{~nm}$ using an ELISA plate reader (PeproTech China, Suzhou, China). A control without cells was used to measure the background absorbance of the medium and was subtracted from the results.

Annexin V/PI assays for apoptosis. For Annexin V/PI assays, cells were stained with Annexin V-FITC and PI, and evaluated for apoptosis by flow cytometry according to the manufacturer's protocol (BD Biosciences Pharmingen, San Diego, CA, USA). Cells were treated with different concentrations of orexin $\mathrm{A}$ in the absence of serum for $48 \mathrm{~h}$. Briefly, cells $\left(1 \times 10^{5}\right)$ were washed twice with PBS, and stained with $5 \mu 1$ of Annexin V-FITC and $10 \mu \mathrm{l}$ of PI in $500 \mu \mathrm{l}$ binding buffer for $15 \mathrm{~min}$ at room temperature in the dark. Quantification of apoptosis was determined by counting the number of cells stained by FITC-labeled Annexin V. Cell apoptosis was detected using the Annexin V/PI apoptosis detection kit by FACS analysis. Early apoptotic cells were identified as PI-negative and FITC Annexin V-positive, while late apoptotic or dead cells were considered FITC Annexin V- and PI-positive.

Total RNA isolation and reverse transcription (RT)-PCR . Total-RNA was extracted from hepatocytes using TRIzol reagent (Invitrogen). The expression of OX1R mRNA in hepatocytes was detected by RT-PCR using TaqMan reagents (Takara Bio, Otsu, Japan). The specific primers used were: OX1R forward, 5'-TGC GGC CAA CCC TAT CAT CTA-3'; and reverse, 5'-ACC GGC TCT GCA AGG ACA A-3'. As an internal control for reverse transcription and reaction efficiency, amplification of glyceraldehyde-3-phosphate dehydrogenase (GAPDH) mRNA was carried out concomitantly for each sample. The primers used were: GAPDH forward, 5'-GGC ACA GTC AAG GCT GAG AAT G-3'; and reverse, 5'-ATG GTG GTG AAG ACG CCA GTA-3'. The PCR reactions were carried out under the following conditions: $95^{\circ} \mathrm{C}$ for $30 \mathrm{sec}$, then 40 cycles of $95^{\circ} \mathrm{C}$ for $5 \mathrm{sec}, 60^{\circ} \mathrm{C}$ for $30 \mathrm{sec}$, and $95^{\circ} \mathrm{C}$ for $15 \mathrm{sec}$. Primers and TaqMan probes specific to OX1R and GAPDH were designed using Primer Premier 5.0 software (Premier Biosoft International, Palo Alto, CA, USA).

Protein preparations and western blot analysis. Cell lysates were incubated on ice for $30 \mathrm{~min}$ and centrifuged at $12,000 \mathrm{xg}$ for $10 \mathrm{~min}$ at $4^{\circ} \mathrm{C}$. The supernatants were collected and mixed with $5 \mathrm{X}$ loading buffer, then denatured by boiling for $10 \mathrm{~min}$. Lysate protein samples were separated by SDS-PAGE and transferred to polyvinylidene fluoride (PVDF) membranes at $70 \mathrm{~V}$ for $1.5 \mathrm{~h}$ in a transfer buffer containing $20 \mathrm{mM}$ Tris, $150 \mathrm{mM}$ glycine and $20 \%$ methanol. The membranes were incubated in non-fat dry milk for $120 \mathrm{~min}$ at room temperature, and then washed three times with TBST for $30 \mathrm{~min}$. The PVDF membranes were incubated in TBST with primary antibodies: phospho/total-OX1R at a 1:250 dilution, phospho/ total-AKT at a 1:1,000 dilution, phospho/total-FoxO1 at a 1:1,000 dilution and phospho/total-mTORC1 at a 1:1,000 dilution overnight at $4^{\circ} \mathrm{C}$, respectively. The membranes were washed and incubated with horseradish peroxidase-conjugated anti-species secondary antibody for $1.5 \mathrm{~h}$ at room temperature, then washed three times with TBST for $30 \mathrm{~min}$. The proteins were visualized by ECL and densities were measured using Quantity-One software. 
A



B
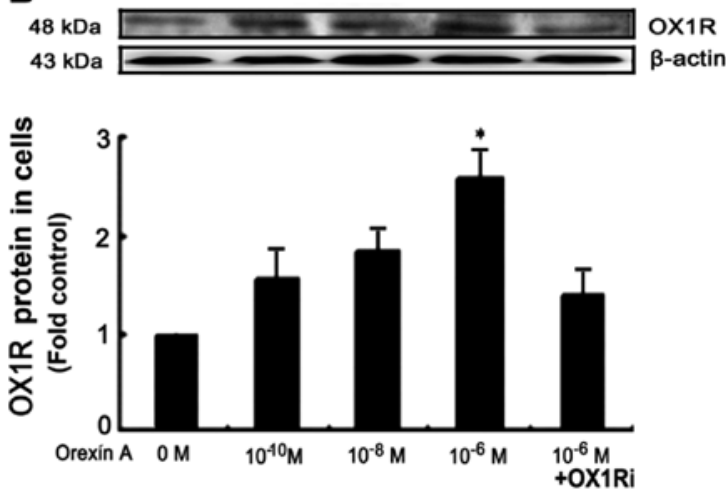

Figure 1. Expression of orexin receptor 1 (OX1R) in mRNA and protein activation in hepatocytes. Cells were cultured and treated with orexin $\mathrm{A}$ $\left(10^{-10}\right.$ to $\left.10^{-6} \mathrm{M}\right)$ for $30 \mathrm{~min}$. (A) OX1R mRNA expressions and phosphorylation were detected by reverse transcription (RT)-PCR and (B) western blot analysis respectively. OX1R protein phosphorylation was then assessed following treatment with $10^{-8} \mathrm{M}$ orexin A and $10^{-6} \mathrm{M}$ SB334867 AKT inhibitor (AKTi) for $30 \mathrm{~min}$. The results are expressed as means \pm SEM. $\mathrm{P}<0.05$ was considered statistically significant. $\mathrm{P}<0.05$ vs. control, $\mathrm{n}=6$.

Statistical analysis. Data was shown as means \pm SEM. One-way analysis of variance (ANOVA) was used for multiple group comparisons. Unpaired t-tests were used for two-group comparisons. Correlation analysis was carried out using Pearson's correlation analysis. $\mathrm{P}<0.05$ was considered statistically significant $(\mathrm{n}=6)$. Statistical analysis was performed using the SPSS 15.0 software package (SPSS Inc., Chicago, IL, USA).

\section{Results}

Effects of orexin A on OXIR in $M R N A$ expression and protein activation in hepatocytes. Rat hepatocytes were were treated with orexin A at concentrations of $0,10^{-10}, 10^{-8}, 10^{-6} \mathrm{M}$ for 30 min respectively. RT-PCR analysis with the use of specific paired primers was used to demonstrate the OX1R mRNA expression in hepatocytes. Orexin $\mathrm{A}\left(10^{-10}, 10^{-8}\right.$ and $\left.10^{-6} \mathrm{M}\right)$ induced a significant increase of OX1R mRNA levels in a dose-dependent manner. A $10^{-6} \mathrm{M}$ orexin A-induced OX1R mRNA expression in the presence of OX1R antagonist SB334867 (10-5 M, $30 \mathrm{~min})$ showed no significant differences compared with the $10^{-6} \mathrm{M}$ orexin A treatment alone (Fig. 1A). The level of OX1R phosphorylation was determined by western blot analysis. We observed that exogenous orexin A upregulated OX1R in the protein level in a dose-dependent manner. Maximum stimulation was identified at $10^{-6} \mathrm{M}$ orexin A treatment and minimum at $10^{-10} \mathrm{M}$ treatment

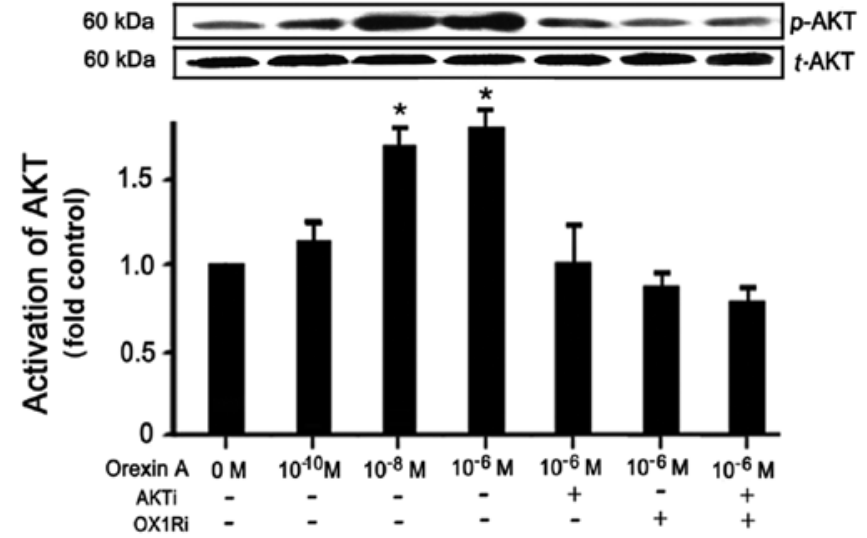

Figure 2. Effects of orexin A on AKT phosphorylation in hepatocytes. To determine the correlation of orexin receptor 1 (OX1R)-induced AKT phosphorylation in hepatocytes, the cells were treated with orexin A at different concentrations $\left(0,10^{-10}, 10^{-8}\right.$ and $\left.10^{-6} \mathrm{M}\right)$ for $30 \mathrm{~min}$. Total-AKT and phospho-AKT levels were determined by western blot analysis. Then OX1R antagonist (OX1Ri, SB334867, $10^{-5} \mathrm{M}, 30 \mathrm{~min}$ ) and AKT inhibitor (AKTi, LY294002, $25 \mu \mathrm{mol} / 1,24 \mathrm{~h}$ ) were used to detect the intracellular mechanisms of the orexin-induced signaling pathway. The results are expressed by means \pm SEM. $P<0.05$ was considered to be statistically significant, $n=6$.

(Fig. 1B). OX1R phosphorylation was reduced in the presence of $10^{-5} \mathrm{M} \mathrm{SB334867}$, an OX1R-specific antagonist (Fig. 1B).

Effects of orexin A on AKT phosphorylation in hepatocytes. To determine the correlation of OX1R-induced AKT phosphorylation in hepatocytes, the cells were treated with orexin $\mathrm{A}$ at different concentrations $\left(0,10^{-10}, 10^{-8}\right.$ and $\left.10^{-6} \mathrm{M}\right)$ for $30 \mathrm{~min}$. The total AKT and phospho-AKT levels were determined by western blot analysis. As compared to basal levels, orexin A induced maximum AKT phosphorylation at the concentration of $10^{-6} \mathrm{M}$ and minimum at $10^{-10} \mathrm{M}$ (Fig. 2). Total AKT remained unchanged (Fig. 2). OX1R antagonist (SB334867, 10-5 M, $30 \mathrm{~min}$ ) and AKT inhibitor (LY294002, $25 \mu \mathrm{mol} / 1,24 \mathrm{~h}$ ) were then used to detect the intracellular mechanisms of the orexin-induced signaling pathway. AKT phosphorylation was abolished in cells treated with the two blockers. Thus, orexin A induced AKT phosphorylation through an OX1R-dependent signaling pathway in hepatocytes (Fig. 2).

Effects of orexin A on FoxOl phosphorylation in hepatocytes. To determine the effects of orexin A on FoxO1 phosphorylation in hepatocytes, the cells were treated with orexin A at different concentrations $\left(0,10^{-10}, 10^{-8}\right.$ and $\left.10^{-6} \mathrm{M}\right)$ for $30 \mathrm{~min}$. Total FoxO1 and phospho-FoxO1 levels were determined by western blot analysis. Orexin A induced maximum FoxO1 phosphorylation at the concentration of $10^{-6} \mathrm{M}$ and minimum at $10^{-10} \mathrm{M}$, while total FoxO1 remained unchanged (Fig. 3A). OX1R antagonist (SB334867, $10^{-5} \mathrm{M}$ ) was used to preincubate hepatocytes for $30 \mathrm{~min}$ in the presence of orexin A $\left(10^{-6} \mathrm{M}, 30 \mathrm{~min}\right)$. FoxO1 phosphorylation was abolished in the cells treated with SB334867. Thus, orexin A induced FoxO1 phosphorylation through OX1R-mediated signaling cascades. Hepatocytes were treated with orexin A $\left(10^{-6} \mathrm{M}\right)$ in the presence of PI3K/AKT inhibitor LY294002 pretreatment ( $25 \mu \mathrm{mol} / 1,24 \mathrm{~h}$ before) and FoxO1 phosphorylation was 


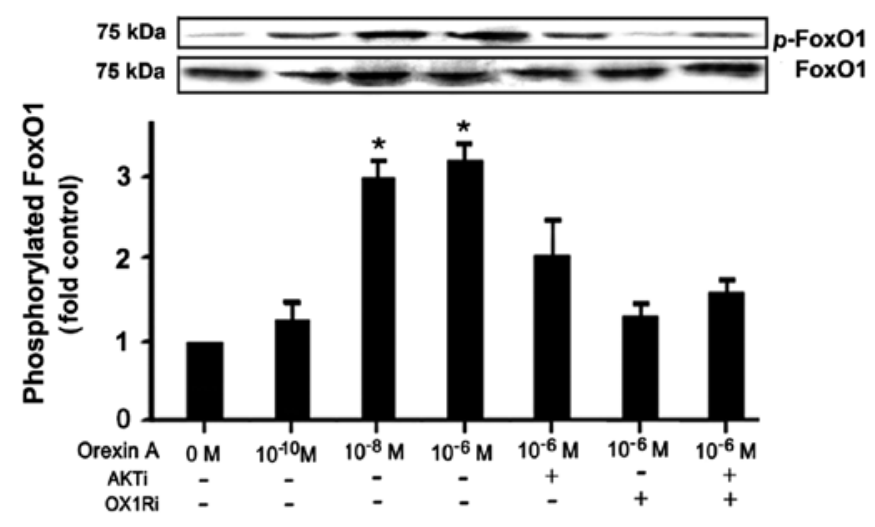

Figure 3. Effects of orexin A on forkhead box O1 (FoxO1) phosphorylation in hepatocytes. To determine the effects of orexin A on FoxO1 phosphorylation in hepatocytes, the cells were treated with orexin A $\left(10^{-10}\right.$ to $\left.10^{-6} \mathrm{M}\right)$ for 30 min. Total FoxO1 and phospho-FoxO1 levels were determined by western blot analysis. The OX1R antagonist (OX1Ri, SB334867, 10 ${ }^{-5} \mathrm{M}$ ) was used to pre-incubate hepatocytes for $30 \mathrm{~min}$ in the presence of orexin $\mathrm{A}\left(10^{-6} \mathrm{M}\right)$. Hepatocytes were treated with orexin $\mathrm{A}\left(10^{-6} \mathrm{M}\right)$ in the presence of the pretreated PI3K/AKT inhibitor LY294002 [AKT inhibitor (AKTi), $25 \mu \mathrm{mol} / 1$ $24 \mathrm{~h}$ before] and FoxO1 phosphorylation was measured by western blot analysis. Additionally, hepatocytes were pretreated with the simultaneous combination of SB334867 and LY294002, and then orexin A (10-6 M) was treated for $30 \mathrm{~min}$. The results are expressed as means $\pm \mathrm{SEM}$. $\mathrm{P}<0.05$ was considered statistically significant, $\mathrm{n}=6$.

measured by western blotting. In the presence of LY294002, the phosphorylated activity of PI3K/AKT was blocked, thus FoxO1 phosphorylation was significantly reduced compared with cells incubated with orexin A $\left(10^{-6} \mathrm{M}\right)$ alone. Additionally, hepatocytes were pretreated with a combination of SB334867 and LY294002 simultaneously, then orexin A $\left(10^{-6} \mathrm{M}\right)$ was treated for $30 \mathrm{~min}$. Results of the western blot analysis revealed that either SB334867 or LY294002 significantly suppressed orexin A-induced FoxO1 phosphorylation, and that there is no differences between the two inhibitory effects. The blockage of either OX1R or PI3K/AKT suppressed FoxO1 phosphorylation. However, with the simultaneous combination of SB334867 and LY294002, FoxO1 phosphorylation was significantly suppressed, compared with treated orexin A $\left(10^{-6} \mathrm{M}\right)$ alone. It suggested an excitatory effect of orexin A on FoxO1 phosphorylation through the OX1R-mediated PI3K/AKT signaling pathway (Fig. 3B).

Effects of orexin-A on mTORC1 phosphorylation in hepatocytes. Hepatocytes were incubated and stimulated with various concentrations $\left(10^{-10}\right.$ to $\left.10^{-6} \mathrm{M}\right)$ of orexin A for $30 \mathrm{~min}$. Alternatively, the cells were treated with $10^{-6} \mathrm{M}$ orexin A combined with the AKT antagonist LY294002 (25 $\mu \mathrm{mol} / \mathrm{l})$ or OX1R antagonist SB334867 (10-6 M). Western blot analysis was used to detect phospho-mTORC1 (p-mTORC1) and total mTORC1 proteins. The effect of $10^{-6}$ and $10^{-8} \mathrm{M}$ orexin A reached statistical significance compared to the control $(\mathrm{p}<0.05)$ (Fig. 4A). p-mTORC1 was then measured to determine whether it was affected by the OX1R antagonist and AKT inhibitor. This effect disappeared in the presence of AKT antagonist LY294002 $(25 \mu \mathrm{mol} / \mathrm{l})$ or OX1R antagonist (SB334867, $10^{-6} \mathrm{M}$ ), as well as their simultaneous combination (Fig. 4B). No statistical difference was identified for the two blockers alone or in combination (Fig. 4B).
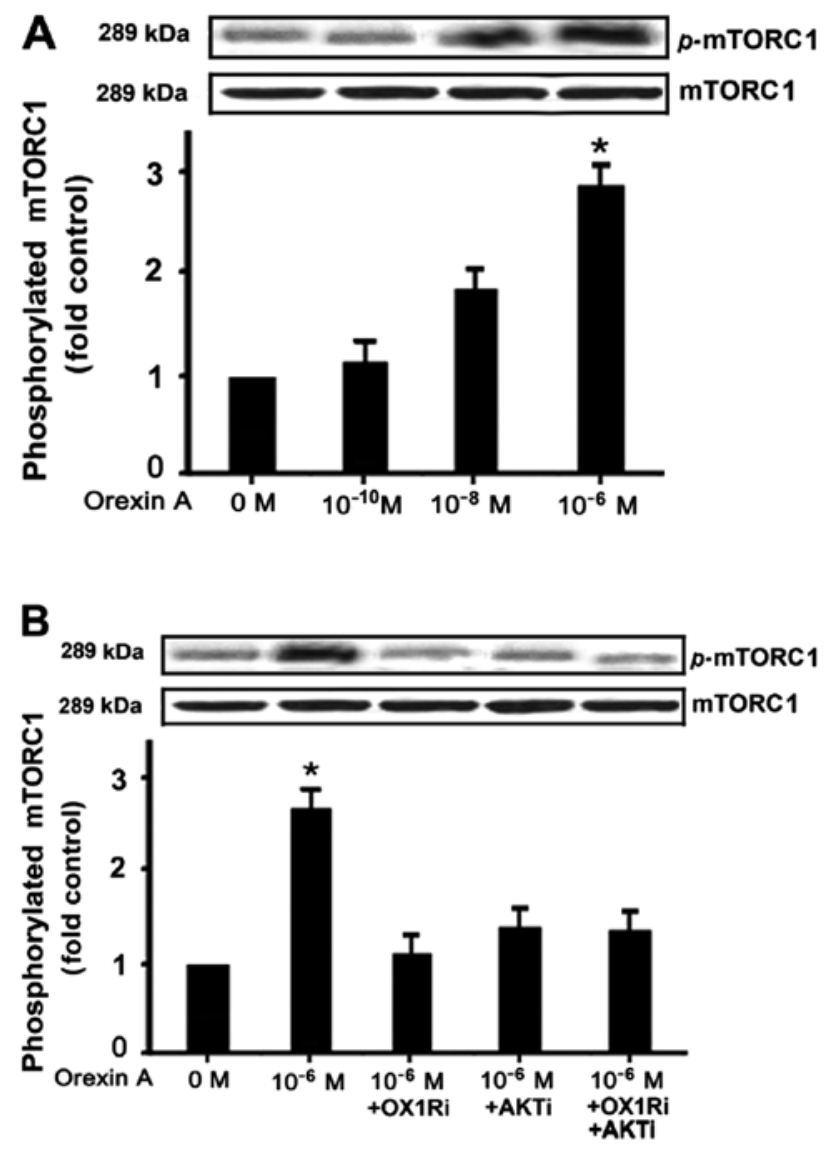

Figure 4. (A) Effects of orexin A on the mammalian target of rapamycin 1 (mTORC1) phosphorylation in hepatocytes. Cells were incubated for $24 \mathrm{~h}$ at $37^{\circ} \mathrm{C}$ and stimulated with various concentrations $\left(0,10^{-10}\right.$, $10^{-8}$ and $10^{-6} \mathrm{M}$ ) of orexin A for $30 \mathrm{~min}$. (B) Alternatively, cells were treated with $10^{-6} \mathrm{M}$ orexin A combined with AKT antagonist LY294002 (AKTi, $25 \mu \mathrm{mol} / 1,24 \mathrm{~h}$ ) or OX1R antagonist SB334867 (OX1Ri, 10 ${ }^{-5} \mathrm{M}, 30 \mathrm{~min}$ ) or their simultaneous combination. (A) Western blot analysis was used to detect phospho-mTORC1 (p-mTORC1) and total mTORC1 proteins. (B) p-mTORC1 was measured to determine whether it was affected by the orexin receptor $1(\mathrm{OX} 1 \mathrm{R})$ antagonist and AKT inhibitor. The results are expressed as means \pm SEM. $\mathrm{P}<0.05$ was considered statistically significant, $\mathrm{n}=6$.

Effects of orexin A on cell proliferation and apoptosis in hepatocytes. To confirm the effects of orexin A-mediated proliferation and apoptosis in hepatocytes, we stimulated hepatocytes with orexin A $\left(10^{-10}\right.$ to $\left.10^{-6} \mathrm{M}\right)$ for $24 \mathrm{~h}$. BrdU analysis was used to determine cell proliferation. Orexin A upregulated cell proliferation in a dose-dependent manner (Fig. 5A). This proliferation-stimulating effect was blocked by the OX1R antagonist SB334867 (10-6 M), AKT inhibitor LY294002 $\left(10^{-6} \mathrm{M}\right)$ or mTORC1 inhibitor everolimus $\left(10^{-5} \mathrm{M}\right)$ (Fig. 5A). A significant decrease in the presence of all three blockers was observed although no significant difference was identified between the individual blockers. However, in the presence of FoxO1 inhibitor, AS1842856, cell proliferation was significantly increased compared with the orexin A treatment alone. This is in contrast with other inhibitors (Fig. 5A). Orexin A treatment $\left(10^{-10}\right.$ to $\left.10^{-6} \mathrm{M}\right)$ resulted in a decrease in the apoptotic index as measured by Annexin V/PI analysis. Orexin A $\left(10^{-10}\right.$ to $\left.10^{-6} \mathrm{M}\right)$ downregulated cell apoptosis in a dose-dependent manner and protected hepatocytes from apoptosis (Fig. 5B). However, it failed to prevent cells from apoptosis in the presence of OX1R 

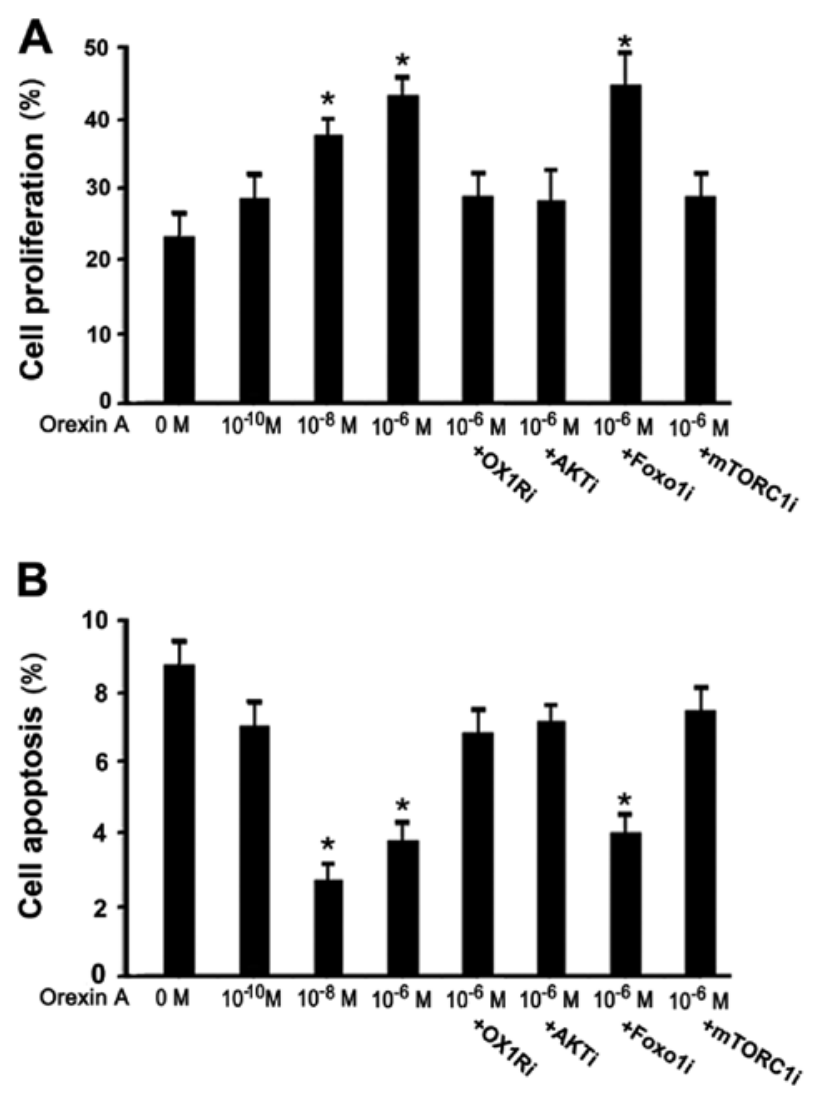

Figure 5. (A and B) Effects of orexin A on cell proliferation and apoptosis in hepatocytes. To confirm the effects of orexin A-mediated proliferation and apoptosis in hepatocytes, we stimulated hepatocytes with orexin A $\left(10^{-10}\right.$ to $\left.10^{-6} \mathrm{M}\right)$ for $24 \mathrm{~h}$. Orexin receptor 1 (OX1R) antagonist SB334867 (OX1Ri, $10^{-5} \mathrm{M}, 30 \mathrm{~min}$ ), AKT inhibitor LY294002 (AKTi, $25 \mu \mathrm{mol} / 1$, 24 h), FoxO1 inhibitor AS1842856 (FoxO1i, 10 ${ }^{-6}$ M, 24 h) and mammalian target of rapamycin 1 (mTORC1) inhibitor everolimus (mTORC1i, 10 ${ }^{-5} \mathrm{M}$, $18 \mathrm{~h}$ ) were then used to investigate the intracellular mechanism. BrdU and Annexin V/PI analysis were used to determine cell proliferation and apoptosis. The results are expressed as means \pm SEM. $\mathrm{P}<0.05$ was considered statistically significant, $\mathrm{n}=6$.

antagonist, AKT inhibitor or mTORC1 inhibitor (Fig. 5B). In the presence of FoxO1 inhibitor, AS1842856, the effect of preventing cells from apoptosis was enhanced, which was in contrast with other inhibitors (Fig. 5B).

\section{Discussion}

Orexin $\mathrm{A}$ is involved in the activation of PI3K/AKT signaling pathways in many peripheral organs and cells $(3,26)$. Orexins elicit their biological effects via GPCRs, OX1R and OX2R, which can signal through multiple $G$ proteins $(27,28)$. The RT-PCR and western blot analysis showed the expression of OX1R in the mRNA and protein levels in hepatocytes, which appears to be hypersensitive to exogenous orexin A stimulation in a dose-dependent manner. The results of this study suggest that orexin A exerted its biological effects by the ligand-induced upregulation of OX1R. A higher concentration of orexin A increases the expression of OX1R. Findings of previous studies have demonstrated the expression of OX1R in many cell types in human and rodents, suggesting that the effects of orexin A are mediated through a direct interaction with OX1R (29-31). The effects of orexin A may be mediated through a specific interaction with the corresponding GPCR. However, the physiological relevance of OX1R expression in hepatocytes remains to be investigated.

$\mathrm{PI} 3 \mathrm{~K} / \mathrm{AKT}$ is an important signaling pathway involved in many cell processes and metabolisms $(23,24)$. As shown in the present study, orexin A upregulated AKT phosphorylation in a dose-dependent manner, while SB334867, an OX1R-specific antagonist was able to block this transduction. We suggest that orexin A activates AKT through an OX1R-mediated pathway. Orexin A stimulates hepatocyte proliferation and protects against apoptotic cell death via the PI3K/AKT-dependent mechanism. Prolonged $(24 \mathrm{~h})$ incubation of hepatocytes with orexin A enhanced cell proliferation and prevented apoptotic cell death. These effects of orexin A were reversed by blocking the PI3K/AKT pathway, indicating that orexin A stimulates hepatocyte proliferation and protects against apoptotic cell death via the PI3K/AKT pathway. The inhibition of AKT by LY294002 is well established, however, the deactivation of AKT inhibited proliferation and failed to prevent apoptosis. Although in this study, activation of AKT by orexin A increased cell proliferation, the manner in which AKT affects these processes and the identity of critical downstream effectors remains largely unknown. To elucidate the mechanism through which AKT affects cell cycle progression, we focused on two evolutionarily conserved downstream effectors of PI3K/AKT, FoxO1 and mTORC1 (32). The two factors play key roles but have an opposite effect in regulating cell proliferation and apoptosis (33-37). This is consistent with the results obtained in the present study.

FoxO1 is a dominant regulator of hepatic gene expression that is usually inactivated through the PI3K/AKT branch of the exogenous stimulator-induced signaling system $(32,38)$. Findings of previous studies have shown that FoxO1 regulates cell proliferation through the transcriptional activation of certain genes $(32,38-40)$. Our data show that FoxO1 was phosphorylated by orexin A and thus lost its transcriptional activity in regulating genes associated with cell processes $(14,15,39,40)$. FoxO1 has been found to play a critical role in the cell cycle processes of rats $(41,42)$ as it suppresses cell proliferation and promotes apoptotic cell death (41-44). FoxO1 suppresses cell proliferation as it activates the expression of the eukaryotic initiation factor 4E-BP-1, which is a major potent proliferation suppressor $(39,40)$. FoxO1 has been shown to directly increase the expression of certain pro-apoptotic proteins such as Bim and BAD $(43,44)$. In previous studies, FoxO1 is defined as a tumor suppressor and its activation has a therapeutic advantage for cancer (45-47).

As another downstream target of PI3K/AKT signaling pathway, mTORC1 promotes cell proliferation and prevents apoptosis $(21,32)$. It regulates cell proliferation largely through an increase in protein synthesis $(32,44)$. mTORC1 regulates proliferation in eukaryotic cells $(33-35,45)$ and inhibits the key proliferation repressor 4E-BP-1 by phosphorylation, thereby increasing cell proliferation $(39,40)$. However, as an evolutionarily conserved downstream target of AKT, FoxO1 is capable of suppressing mTORC1 activity $(21,32,42)$. FoxO1 is thought to have tumor suppressive activity $(46,47)$, whereas mTORC1 is frequently activated in cancer cells (48).

Orexin A is identified as an endocrine effector that activates mTORC1 but which inhibits FoxO1-dependent gene regulation 
in a PI3K/AKT-dependent manner. As shown in results of the present study, orexin A promotes hepatocyte proliferation and protects against apoptosis. Orexin A deactivates FoxO1 and activates mTORC1 activity by phosphorylation, which co-affects proliferation-promotion and apoptosis-prevention in hepatocytes. Inhibition of FoxO1 with AS1842856 increases cell proliferation and suppresses apoptosis. Inhibition of mTORC1 with everolimus suppresses cell proliferation and increases apoptosis. In this study, it was shown that orexin A enhances cell proliferation and attenuates apoptosis. These effects are signaled by altering FoxO1 (deactivate) and mTORC1 (activate) activity. In this cell cycle process, FoxO1 and mTORC1 play two opposing roles in the regulation of cell proliferation and apoptosis.

In summary, our findings provide evidence that orexin A increased cell proliferation and protected cells from apoptosis, an effect that is signaled via PI3K/AKT cascades by suppressing FoxO1 and enhancing mTORC1 activity by phosphorylation. Orexin A may exert apoptotic function in a FoxO1 and mTORC1-dependent manner. Therefore, understanding the cellular mechanisms of action of orexin A in hepatocytes is crucial in gaining insight into the therapeutic role of orexin A in the regulation of a variety of cell cycle processes. For these reasons, we predict that drug interference in conjunction with mTORC1 or FoxO1 action may be used in clinical practice to improve human health in the future. Orexin A has evolved to accelerate proliferation and suppress apoptosis, while also increasing the incidence of cancer, metabolic derangement and aging in patients. Ongoing investigations should therefore focus on the relationship between orexin A and its clinical implications.

\section{Acknowledgements}

We would like to thank the China Medical University Affiliated Hospital Laboratory Center for kindly providing equipment required. This study was supported by the National Natural Science Foundation of China (grant nos. 30872724, 81071460, and 81271996), the Natural Science Foundation of Liaoning Province (grant no. 201202292).

\section{References}

1. De Lecea L, Kilduff TS, Peyron C, Gao X, et al: The hypocretins: hypothalamus-specific peptides with neuroexcitatory activity. Proc Natl Acad Sci USA 95: 322-327, 1998.

2. Sakurai T, Amemiya A, Ishii M, Matsuzaki I, Chemelli RM Tanaka H, et al: Orexins and orexin receptors: a family of hypothalamic neuropeptides and $\mathrm{G}$ protein-coupled receptors that regulate feeding behavior. Cell 92: 573-585, 1998.

3. Karteris E and Randeva HS: Orexin receptors and G-protein coupling: evidence for another 'promiscuous' seven transmembrane domain receptor. J Pharmacol Sci 93: 126-128, 2003.

4. Date Y, Ueta Y, Yamashita H, Yamaguchi H, Matsukura S, Kangawa K, Sakurai T, Yanagisawa M and Nakazato M: Orexins, orexigenic hypothalamic peptides, interact with autonomic, neuroendocrine and neuroregulatory systems. Proc Natl Acad Sci USA 96: 748-753, 1999.

5. Nambu T, Sakurai T, Mizukami K, Hosoya Y, Yanagisawa M and Goto K: Distribution of orexin neurons in the adult rat brain Brain Res 827: 243-260, 1999.

6. Peyron C, Tighe DK, van den Pol AN, de Lecea L, Heller HC, Sutcliffe JG and Kilduff TS: Neurons containing hypocretin (orexin) project to multiple neuronal systems. J Neurosci 18: 9996-10015, 1998.
7. Lin L, Faraco J, Li R, Kadotani H, Rogers W, Lin X, Qiu X, de Jong PJ, Nishino S and Mignot E: The sleep disorder canine narcolepsy is caused by a mutation in the hypocretin (orexin) receptor 2 gene. Cell 98: 365-376, 1999.

8. Yokobori E, Kojima K, Azuma M, et al: Stimulatory effect of intracerebroventricular administration of orexin A on food intake in the zebrafish. Peptides 32: 1357-1362, 2011.

9. Spinazzi R, Rucinski M, Neri G, Malendowicz LK and Nussdorfer GG: Preproorexin and orexin receptors are expressed in cortisol-secreting adrenocortical adenomas, and orexins stimulate in vitro cortisol secretion and growth of tumor cells. J Clin Endocrinol Metab 90: 3544-3549, 2005.

10. Ramanjaneya M, Conner AC, Chen J, Stanfield PR and Randeva HS: Orexins stimulate steroidogenic acute regulatory protein expression through multiple signaling pathways in human adrenal H295R cells. Endocrinology 149: 4106-4115, 2008.

11. Beiras-Fernández A, Gallego R, Blanco M, García-Caballero T, Diéguez C and Beiras A: Merkel cells, a new localization of prepro-orexin and orexin receptors. J Anat 204: 117-122, 2004.

12. Jöhren O, Neidert SJ, Kummer M, Dendorfer A and Dominiak P: Prepro-orexin and orexin receptor mRNAs are differentially expressed in peripheral tissues of male and female rats. Endocrinology 142: 3324-3331, 2001.

13. Lawlor MA and Alessi DR: PKB/Akt: A key mediator of cell proliferation, survival and insulin response? J Cell Sci 114: 2903-2910, 2001.

14. Gross DN, Wan M and Birnbaum MJ: The role of FOXO in the regulation of metabolism. Curr Diab Rep 9: 208-214, 2009.

15. Matsumoto M, Pocai A, Rossetti L, Depinho RA and Accili D: Impaired regulation of hepatic glucose production in mice lacking the forkhead transcription factor Foxol in liver. Cell Metab 6: 208-216, 2007.

16. Accili D and Arden KC: FoxOs at the crossroads of cellular metabolism, differentiation, and transformation. Cell 117: 421-426, 2004

17. Yuan Z, Lehtinen MK, Merlo P, Villén J, Gygi S and Bonni A: Regulation of neuronal cell death by MST1-FOXO1 signaling. J Biol Chem 284: 11285-11292, 2009.

18. Kajihara T, Jones M, Fusi L, Takano M, Feroze-Zaidi F, Pirianov G, Mehmet H, Ishihara O, Higham JM, Lam EW and Brosens JJ: Differential expression of FOXO1 and FOXO3a confers resistance to oxidative cell death upon endometrial decidualization. Mol Endocrinol 20: 2444-2455, 2006.

19. Shen B, Chao L and Chao J: Pivotal role of JNK-dependent FOXO1 activation in downregulation of kallistatin expression by oxidative stress. Am J Physiol Heart Circ Physiol 298: H1048-H1054, 2010.

20. Thomas GV: mTOR and cancer: Reason for dancing at the crossroads? Curr Opin Genet Dev 16: 78-84, 2006.

21. Chen CC, Jeon SM, Bhaskar PT, Nogueira V, Sundararajan D, Tonic I, Park Y and Hay N: FoxOs inhibit mTORC1 and activate Akt by inducing the expression of Sestrin3 and Rictor. Dev Cell 18: 592-604, 2010.

22. Zoncu R, Efeyan A and Sabatini DM: mTOR: from growth signal integration to cancer, diabetes and ageing. Nat Rev Mol Cell Biol 12: 21-35, 2011.

23. Chen ML, Xu PZ, Peng XD, Chen WS, Guzman G, Yang X, Di Cristofano A, Pandolfi PP and Hay N: The deficiency of Akt1 is sufficient to suppress tumor development in Pten+/-mice. Genes Dev 20: 1569-1574, 2006.

24. Hahn-Windgassen A, Nogueira V, Chen CC, Skeen JE, Sonenbreg $\mathrm{N}$ and Hay N: Akt activates the mammalian target of rapamycin by regulating cellular ATP level and AMPK activity. J Biol Chem 280: 32081-32089, 2005.

25. Robey RB and Hay N: Mitochondrial hexokinases: Guardians of the mitochondria. Cell Cycle 4: 654-658, 2005.

26. Holmqvist T, Johansson L, Ostman M, Ammoun S, Akerman KE and Kukkonen JP: OX1 orexin receptors couple to adenylyl cyclase regulation via multiple mechanisms. J Biol Chem 280: 6570-6579, 2005.

27. Malendowicz LK, Tortorella C and Nussdorfer GG: Orexins stimulate corticosterone secretion of rat adrenocortical cells, through the activation of the adenylate cyclase-dependent signaling cascade. J Steroid Biochem Mol Biol 70: 185-188, 1999.

28. López M1, Señarís R, Gallego R, García-Caballero T, Lago F, Seoane L, Casanueva F and Diéguez C: Orexin receptors are expressed in the adrenal medulla of the rat. Endocrinology 140: 5991-5994, 1999. 
29. Göncz E, Strowski MZ, Grötzinger C, Nowak KW, Kaczmarek P, Sassek M, Mergler S, El-Zayat BF, Theodoropoulou M, Stalla GK, Wiedenmann B and Plöckinger U: Orexin-A inhibits glucagon secretion and gene expression through a Foxo1-dependent pathway. Endocrinology 149: 1618-1626, 2008.

30. Ramanjaneya M1, Conner AC, Chen J, Kumar P, Brown JE, Jöhren O, Lehnert H, Stanfield PR and Randeva HS: Orexin-stimulated MAP kinase cascades are activated through multiple G-protein signaling pathways in human H295R adrenocortical cells: diverse roles for orexins A and B. J Endocrinol 202: 249-261, 2009

31. Zhu Y, Miwa Y, Yamanaka A, Yada T, Shibahara M, Abe Y, Sakurai T and Goto K: Orexin receptor type-1 couples exclusively to pertussis toxin insensitive G-proteins, while orexin receptor type-2 couples to both pertussis toxin-sensitive and -insensitive G-proteins. J Pharmacol Sci 92: 259-266, 2003.

32. Skeen JE, Bhaskar PT, Chen CC, Chen WS, Peng XD, Nogueira V, Hahn-Windgassen A, Kiyokawa $\mathrm{H}$ and Hay N: Akt deficiency impairs normal cell proliferation and suppresses oncogenesis in a p53-independent and mTORC1-dependent manner. Cancer Cell 10: 269-280, 2006.

33. Kapahi P, Chen D, Rogers AN, Katewa SD, Li PW, Thomas EL and Kockel L: With TOR, less is more: a key role for the conserved nutrient-sensing TOR pathway in aging. Cell Metab 11: 453-465, 2010.

34. Wang $X$ and Proud CG: Nutrient control of TORC1, a cell-cycle regulator. Trends Cell Biol 19: 260-267, 2009.

35. Gera JF, Mellinghoff IK, Shi Y, Rettig MB, Tran C, Hsu JH, Sawyers CL and Lichtenstein AK: AKT activity determines sensitivity to mammalian target of rapamycin (mTOR) inhibitors by regulating cyclin D1 and c-myc expression. J Biol Chem 279: 2737-2746, 2004.

36. Buteau J and Accili D: Regulation of pancreatic beta-cell function by the forkhead protein FoxO1. Diabetes Obes Metab 9: 140-146, 2007.

37. Cheng Z and White MF: Targeting forkhead box O1 from the concept to metabolic diseases: lessons from mouse models. Antiox Redox Signal 14: 649-661, 2011.
38. Puthanveetil P, Wan A and Rodrigues B: FoxO1 is crucial for sustaining cardiomyocyte metabolism and cell survival. Cardiovasc Res 97: 393-403, 2013.

39. Jünger MA, Rintelen F, Stocker H, Wasserman JD, Végh M, Radimerski T, Greenberg ME and Hafen E: The Drosophila forkhead transcription factor FOXO mediates the reduction in cell number associated with reduced insulin signaling. J Biol 2: 20, 2003.

40. Puig O, Marr MT, Ruhf ML and Tjian R: Control of cell number by Drosophila FOXO: downstream and feedback regulation of the insulin receptor pathway. Genes Dev 17: 2006-2020, 2003.

41. Zeng FY, Cui J, Liu L and Chen T: PAX3-FKHR sensitizes human alveolar rhabdomyosarcoma cells to camptothecinmediated growth inhibition and apoptosis. Cancer Lett 284: 157-164, 2009.

42. Liu P, Kao TP and Huang H: CDK1 promotes cell proliferation and survival via phosphorylation and inhibition of FOXO1 transcription factor. Oncogene 27: 4733-4744, 2008.

43. Fendler A1, Jung M, Stephan C, Erbersdobler A, Jung K and Yousef GM: The antiapoptotic function of miR-96 in prostate cancer by inhibition of FOXO1. PLoS One 8: e80807, 2013.

44. Harada H, Andersen JS, Mann M, Terada N and Korsmeyer SJ: p70S6 kinase signals cell survival as well as growth, inactivating the pro-apoptotic molecule BAD. Proc Natl Acad Sci USA 98: 9666-9670, 2001.

45. Budanov AV and Karin M: p53 target genes sestrin1 and sestrin2 connect genotoxic stress and mTOR signaling. Cell 134: 451-460, 2008.

46. Hay N: Interplay between FOXO, TOR, and Akt. Biochim Biophys Acta 1813: 1965-1970, 2011

47. Dansen TB and Burgering BM: Unravelling the tumorsuppressive functions of FOXO proteins. Trends Cell Biol 18: 421-429, 2008

48. Bhaskar PT and Hay N: The two TORCs and Akt. Dev Cell 12: 487-502, 2007. 